\title{
Numerical modelling of hydrostatic lift pockets in hydrodynamic journal bearings - Application to low speed working conditions of highly loaded tilting pad journal bearings
}

\author{
Xavier Raud ${ }^{1}$, Michel Fillon ${ }^{2}$ and Mathieu Helene ${ }^{1, a}$ \\ 1 Département AMA/Groupe T63, 1 avenue du Général de Gaulle, Bureau IB010, 92141 Clamart Cedex, France \\ 2 Département Génie Mécanique et Systèmes Complexes, CNRS - Université de Poitiers - ENSMA, UPR 3346, SP2MI, \\ Bd Marie et Pierre Curie, BP 30179, 86962 Futuroscope Chasseneuil Cedex, France
}

Received 23 December 2010, Accepted 24 September 2013

\begin{abstract}
Hydrodynamic journal bearings supporting high mass rotating machinery are subjected to low rotational speeds during start-up or idling phases. These working conditions need a hydrostatic pressure contribution to ensure a correct load capacity when the hydrodynamic pressure is not established yet. This is possible by means of hydrostatic lift pockets. These pockets avoid mechanical damages via sufficient film thickness from start-up to hydrodynamic working conditions. In a first part, it is showed how an existing isothermal 3D hydrodynamic numerical modelling of tilting pad bearing has been adapted to take into account the lift pocket impact on static bearing performance. This approach is only valid for low rotational speeds, when inertia step pressure effects (rises or drops) at the film-pocket edge can be neglected compared to the total bearing pressure pattern. Then, numerical simulations have been performed, from 1 to $200 \mathrm{rpm}$ with pockets and from 75 to $200 \mathrm{rpm}$ without pockets. The results have been compared and discussed in terms of pressure fields and bearing static performance such minimum film thickness, friction torque or rotor center position. Therefore, the interest of such lift pockets has been highlighted. Finally, calculations with and without pockets have been carried out in case of a strong bearing misalignment. As a result, the benefits of the lift pockets in this configuration are also significant in terms of static performance.
\end{abstract}

Key words: Hydrostatic lift pockets / hydrostatic lubrication / hydrodynamic lubrication / tilting pad journal bearings

Résumé - Prise en compte numérique de la contribution des poches de soulèvement dans les paliers hydrodynamiques - Application aux cas de fonctionnement à basse vitesse de paliers à patins oscillants fortement chargés. Les paliers hydrodynamiques présents sur les lignes d'arbre de forte masse nécessitent, pour les phases de démarrage et basse vitesse, l'aide d'une pression hydrostatique afin d'assurer leur mission de supportage lorsque la pression hydrodynamique n'est pas encore établie. Les poches de soulèvement hydrostatique présentes dans ces paliers permettent d'assurer cette fonction qui préserve l'intégrité du coussinet en assurant une épaisseur de film mince suffisante dès les premiers tours de la machine. Cette étude présente tout d'abord les modifications apportées à une modélisation 3D hydrodynamique en régime isotherme existante pour prendre en compte l'impact de telles poches sur les caractéristiques statiques du palier. Cette approche se limite à des vitesses de rotation faibles, pour lesquelles les sauts de pression à l'interface film mince/poche (discontinuité géométrique) dus aux effets d'inertie peuvent encore être négligés dans l'allure globale du champ de pression. Puis, des résultats de calculs concernant plusieurs vitesses de rotation allant de 1 à 200 tr.min ${ }^{-1}$ avec poches de soulèvement seront présentés et comparés aux mêmes cas sans poches pour des vitesses allant de 75 à 200 tr.min ${ }^{-1}$.

\footnotetext{
${ }^{a}$ Corresponding author: mathieu.helene@edf.fr
} 
Les champs de pressions et les différentes caractéristiques statiques comme l'épaisseur minimale de film, le couple de frottement, la position du rotor ainsi obtenus, seront analysés dans chaque cas et l'intérêt de ces poches de soulèvement sera mis en avant. Enfin, des calculs avec et sans poches seront également présentés dans le cas d'un fort mésalignement du palier et l'impact favorable des poches sur les caractéristiques statiques sera illustré.

Mots clés : Poches de soulèvement hydrostatiques / lubrification hydrostatique / lubrification hydrodynamique / paliers à patins oscillants

\section{Nomenclature}

\begin{tabular}{|c|c|}
\hline$\mu$ & Dynamic viscosity [Pa.s] \\
\hline$\rho$ & Density $\left[\mathrm{kg} . \mathrm{m}^{3}\right]$ \\
\hline$\omega$ & Bearing rotational speed $\left[\right.$ tr. $\left.\min ^{-1}\right]$ \\
\hline$C_{\mathrm{d}}^{i}$ & $\begin{array}{l}\text { Discharge coefficient for the considered } \\
\text { pocket orifice }\end{array}$ \\
\hline$d_{\text {ori }}^{i}$ & Orifice diameter $[\mathrm{m}]$ \\
\hline$h$ & Film thickness $[\mathrm{m}]$ \\
\hline$k_{x}, k_{z}$ & Local viscosity coefficients \\
\hline$P_{\mathrm{a} \lim }^{i}$ & Feeding pressure upstream orifice $[\mathrm{Pa}]$ \\
\hline$P_{\text {poc }}^{i}$ & $\begin{array}{l}\text { Constant average pressure for the considered } \\
\text { pocket }[\mathrm{Pa}]\end{array}$ \\
\hline$Q_{\mathrm{e} \text {-poc }}^{i}$ & $\begin{array}{l}\text { Flow rate entering the pocket via } \\
\text { film land }\left[\mathrm{m}^{3} \cdot \mathrm{s}^{-1}\right]\end{array}$ \\
\hline$Q_{\text {ori }}^{i}$ & $\begin{array}{l}\text { Flow rate entering the pocket via the } \\
\text { feeding orifice }\left[\mathrm{m}^{3} \cdot \mathrm{s}^{-1}\right]\end{array}$ \\
\hline$R_{\text {ea }}$ & $\begin{array}{l}\text { Average Reynolds number considering film - } \\
\text { recess interface }\end{array}$ \\
\hline$R_{\text {shaft }}$ & Shaft radius $[\mathrm{m}]$ \\
\hline$V_{\mathrm{a}}$ & $\begin{array}{l}\text { Average speed through the film - recess } \\
\text { interface }\left[\mathrm{m} \cdot \mathrm{s}^{-1}\right]\end{array}$ \\
\hline
\end{tabular}

\section{Introduction - context of the study}

EDF nuclear power plants are designed with horizontal axis steam turbines. This type of rotating turbo machinery is equipped with very heavy rotor assemblies (several hundreds of tons). Furthermore, due to large diameters and rotating speeds, hydrodynamic journal bearings come to be the only solution to provide good supporting characteristics. However, this type of bearing has to cope with stop and start-up phases where hydrodynamic lubrication conditions are not established yet. This can lead to difficult start-ups due to high friction torque, bearing wear or even Babbitt destruction. To avoid these issues, the journal bearings are equipped with hydrostatic recesses or "pockets", fed by means of specific oil pumps. Thus, the resulting hydrostatic pressure enables load capacity and avoids rotor/stator contact even before the beginning of the shaft rotation during start-up phases (and before the loss of hydrodynamic lift during the shutdown phases). From the knowledge of the authors, except for the tilting-pad thrust bearings [1], there are no specific studies on the behavior of these rotor lifting systems in the scientific literature. Only few information can be found in general books on Tribology and Lubrication. In their book [2], Khonsari and Booser have indicated that the oil hydraulic lifts are also used during the very low rotational speed operation, i.e. turning speed operation (several revolutions per minute), in order to reduce the friction torque and the wear of the hydrodynamic bearings. In 1984, Ewell [3] gave the relationship of the breakaway pressure and the required oil flow versus the static load and the bearing geometry. It is recommended by the manufacturers [4] to use a hydrostatic system when the specific load at start-up, i.e. specific pressure, is larger than 1.3 MPa for the plain journal bearing configuration and larger than $1.25 \mathrm{MPa}$ for the tilting-pad journal bearing configuration. In another reference book on practical aspects of lubrication, Neale [5] gives the maximum specific load during the start-up phase for the babitted journal bearings: $1.4 \mathrm{MPa}$ for the frequent starts and stops (several times per day) and 2.5 MPa for start and stop once a day or less.

The first part of this paper will be aimed at technological aspects and describe all involved systems: steam turbines, tilting pad journal bearing and hydrostatic lift pockets. The second part will deal with the numerical approach and will explain how an existing isothermal hydrodynamic model [6] has been modified in order to take into account the effect of lift pockets on the bearing static performances. Then, numerical results will be presented in the third part and the benefits of the lift pockets in terms of maximum pressure, minimum film thickness and friction torque for zero and low rotational speeds will be highlighted. Finally, these benefits will be also considered for misaligned bearings and perspectives of misalignment diagnosis via pockets pressure measurements will be discussed.

\section{Technological aspects}

French nuclear power plants turbo generator sets are an assembly of one high pressure steam turbine, three low pressure steam turbines and one alternator, as described in Figure 1. These equipments are supported by seven hydrodynamic tilting pad journal bearings. The geometrical characteristics of such bearings are described in Figure 2, they include three pads, can support loads up to 200 tons and have a rotational speed of $1500 \mathrm{rpm}$. During start-up phases, hydrodynamic lubrication is not established yet and thus, it is necessary to bring a hydrostatic pressure in order to avoid contact between the shaft and the main pad. This is possible by means of several cavities located in the pad (Fig. 3), named "pockets", fed by specific hydraulic pumps. In each pocket, a constant pressure takes place and leads to the lift of the shaft even before it starts 


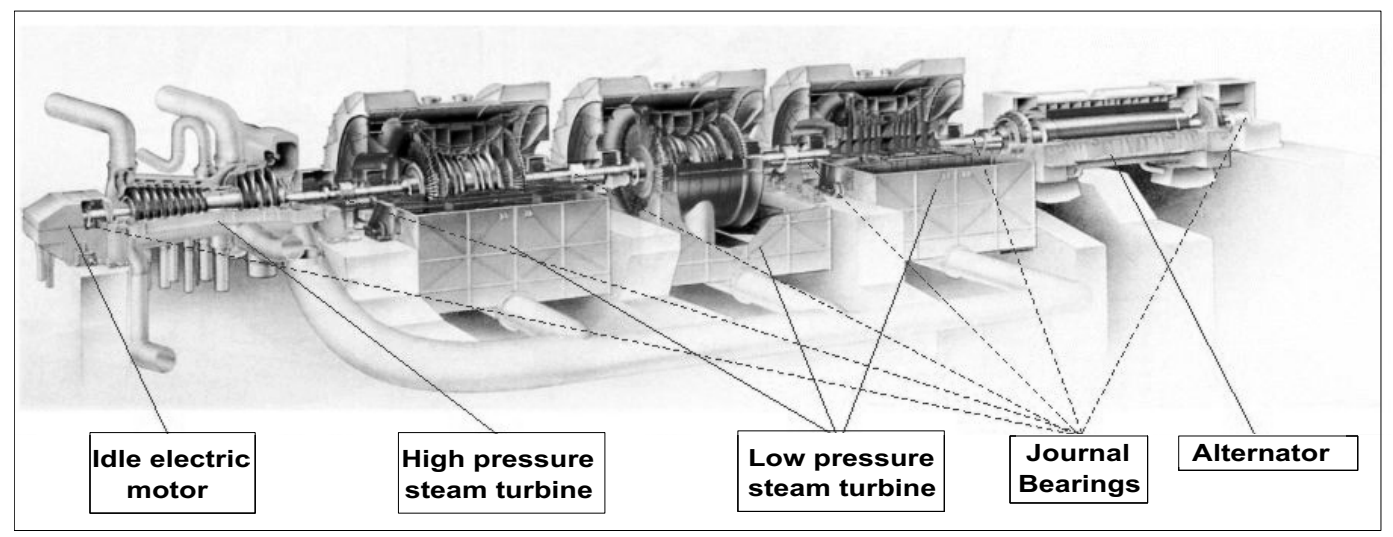

Fig. 1. 1400 MWe turbo generator set.

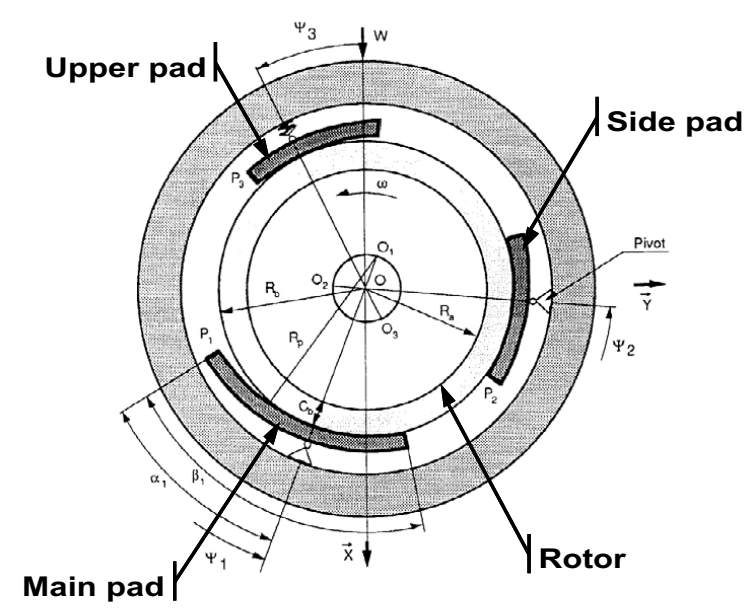

Fig. 2. Geometrical characteristics of tilting pad bearings.

to rotate. By developing the bearing in the circumferential direction, Figure 4 shows in details where the pockets are located in each pad: 4 pockets within the main pad and 2 pockets within the side pad. Concerning the main pad, central pockets (2 and 3) are each fed by one pump whereas external pockets (1 and 4) are coupled and fed by a unique pump. In this case, the 2 pockets feeding ducts provide a hydraulic resistance by means of orifices. Thus, the resulting pressure in such coupled pockets depends on the total group flow rate, on the film thickness in the recesses area and on the local pressure conditions. The interest of such hydraulic structure comes to have all an interest in case of shaft misalignment. In this situation, external pockets zones can experience very different local conditions in term of film thickness and pressure. This can lead to a large difference of flow rates in the 2 pockets. Therefore, hydraulic resistances allow to balance these 2 flow rates and to raise the pressure toward the pocket zone where film thickness is lower (Fig. 5). As a result, this leads to an increase of the minimum film thickness through the pad. This is summarised in Table 1 where a case of bearing misalignment is considered, with and without the existence of the hydraulic resistances in the coupled pockets ducts. With the hydraulic resistance

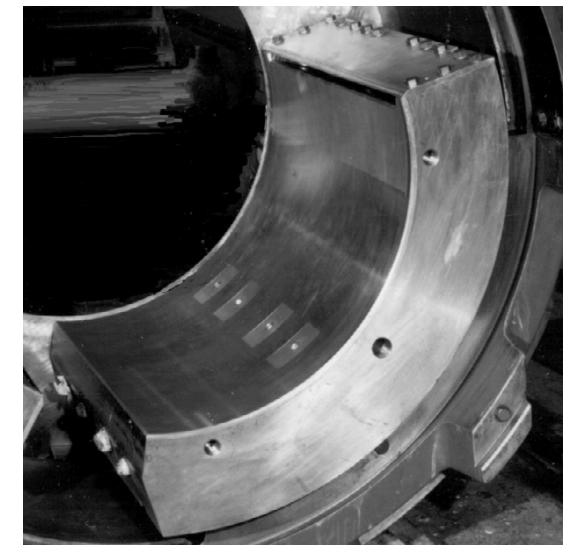

Fig. 3. View of lift pockets on main pad.

and in presence of a misaligned rotor, it is noticeable that flow rates through coupled pockets ( 1 and 4 ) have been balanced. As a result, the pocket pressure toward the minimum film thickness has increased of $72 \%$ and the minimum film thickness has increased of $27 \%$, leading to safer operating conditions.

\section{Numerical approach}

\subsection{Isothermal analysis}

The numerical work is based on EDYOS, a numerical code for lubrication [6]. Classical thin film lubrication hypothesis is considered:

- Isothermal steady state flow.

- Continuous fluid medium: Newtonian, incompressible lubricant, with constant density and dynamic viscosity within all the film land.

- Film thickness depends, on the geometrical characteristics like the radial clearance $\mathrm{C}$ and on the position of the shaft center. It is small compared to the bearing radius and length.

- Surfaces curvature is neglected: the shaft is developed and considered as a plane surface. 
Table 1. Impact of hydraulic resistance in case of misalignment.

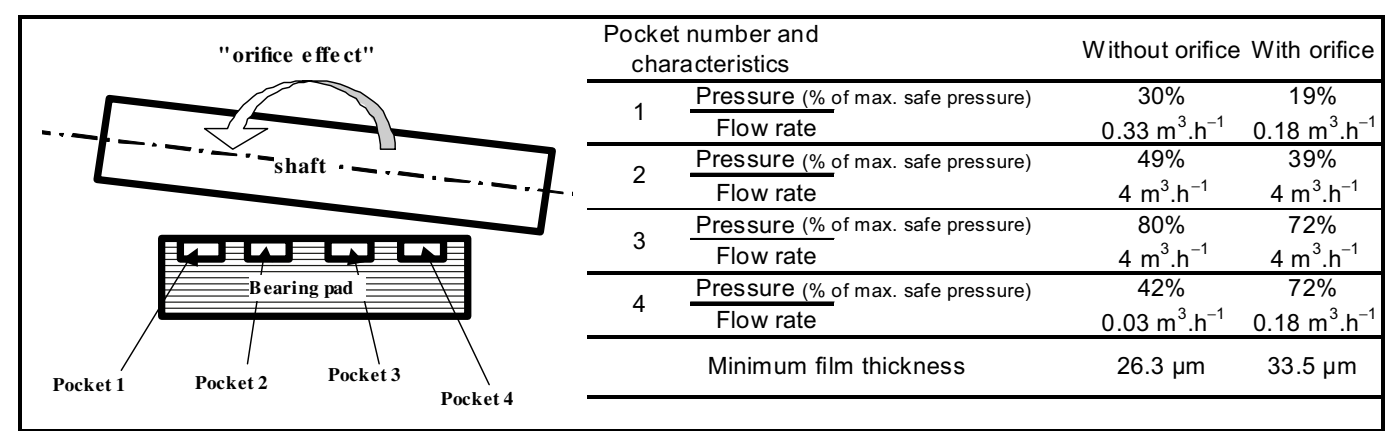
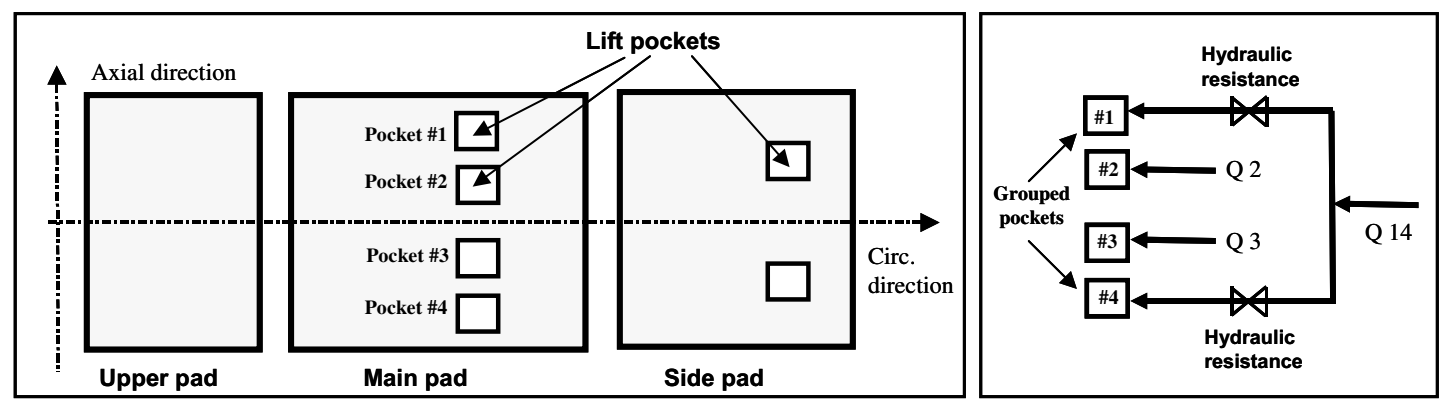

Fig. 4. Pockets location and feeding mode.
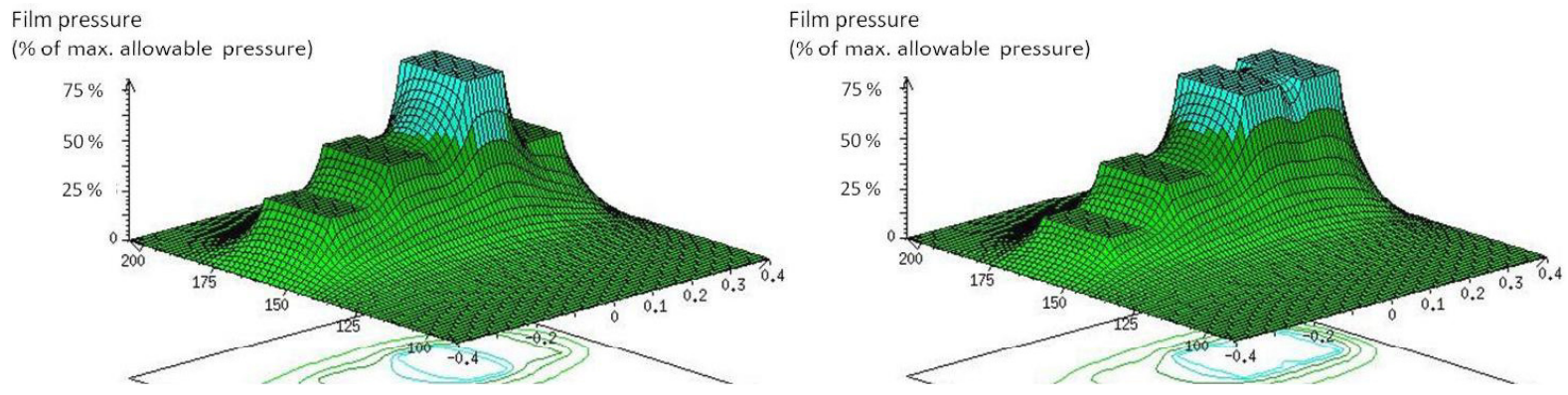

Fig. 5. Effect of hydraulic resistance on pressure field. Left without an orifice - right with an orifice.

- No slip conditions assumption at lubricated contact wall boundaries.

- Inertia forces in the film are neglected.

- In the thin film area, the flow can be turbulent. The Constantinescu model [7] is considered in order to take into account turbulence by introducing viscosity coefficients based on local Couette and Poiseuille Reynolds numbers. The Reynolds equation is then:

$$
\frac{1}{R_{\text {shaft }}^{2}} \frac{\partial}{\partial \theta^{*}}\left(\frac{h^{3}}{k_{x}} \frac{\partial p}{\partial \theta^{*}}\right)+\frac{\partial}{\partial z}\left(\frac{h^{3}}{k_{z}} \frac{\partial p}{\partial z}\right)=\frac{\mu \omega}{2} \frac{\partial h}{\partial \theta^{*}}
$$

where $k_{x}$ and $k_{z}$ are the local viscosity coefficients.

\subsection{Flow rate through pockets modelling}

Pocket pressure is assumed to be a constant and feeding flow rate of the pockets is an input data. The outflow through each pocket edge is obtained by integration of speeds at the film/recess boundary. In case of coupled pockets, it is necessary to calculate the flow rate through each feeding duct orifice.

$$
Q_{\text {e_poc }}^{i}=Q_{\text {ori }}^{i}=C_{\mathrm{d}}^{i} \frac{\pi\left(d_{\text {ori }}^{i}\right)^{2}}{4} \sqrt{\frac{2\left(P_{\text {a } \lim }^{i}-P_{\text {poc }}^{i}\right)}{\rho}}
$$

where:

$C_{\mathrm{d}}^{i}$ is the discharge coefficient for the considered pocket orifice; $d_{\text {ori }}^{i}$ is the orifice diameter of considered pocket.

Another assumption is that velocities are continuous in the film - recess boundary, meaning that inertia step pressure effects (rises or drops) are neglected compared to total bearing pressure pattern. This analysis is then limited to very low film - pocket edges average Reynolds numbers $\operatorname{Re}_{\mathrm{a}}$ :

$$
R e_{\mathrm{a}}=\frac{\rho R_{\mathrm{shaft}} V_{\mathrm{a}}}{\mu}
$$




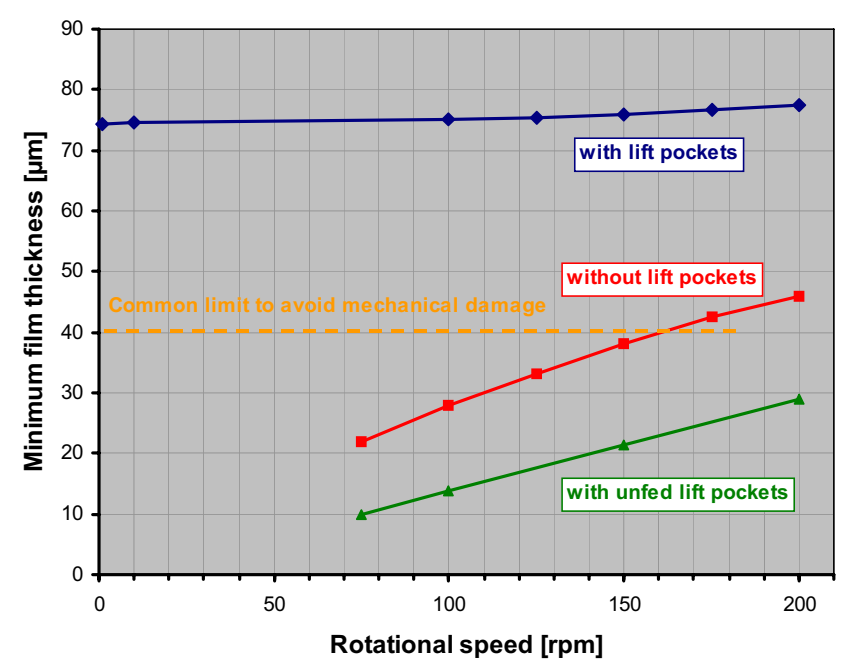

Fig. 6. Minimum film thickness vs. rotor speed.

where: $V_{\mathrm{a}}$ is the average speed through the whole film/recess interface, depending on pocket supply flow rate and shaft rotational speed.

The presence of pockets only affects the pressure field for low shaft rotation speeds and negligible inertia pressure effects. In all calculations of this study, rotational speed was lower than $200 \mathrm{rpm}$, corresponding to very low Couette Reynolds numbers. The Poiseuille Reynolds number, linked to pocket flow rate supply, remains also very low (about 5).

Finally, input data for calculations are the feeding flow rates (for single or coupled pockets), the bearing geometrical characteristics, the lubricant properties, the shaft rotational speed and the load due to the rotor mass. Calculations lead to shaft position in the bearing, pressure field, film thicknesses and pockets pressures.

\section{Results}

Three types of calculations, based on the bearing described in Section 2, have been carried out. First, a hydrodynamic tilting pad journal bearing with no lift pockets has been considered. Then the same bearing with lift pockets has been studied for two different situations: fed and unfed pockets.

\subsection{Static performances}

For the considered bearing, it is recommended to maintain a minimum film thickness greater than $40 \mu \mathrm{m}$. Figure 6 shows the evolution of the minimum film thickness from 0 to $200 \mathrm{rpm}$ for fed pockets and from $75 \mathrm{rpm}$ to $200 \mathrm{rpm}$ for unfed pockets and no pockets cases. These last configurations did not allow further calculations for lower speed due to very low film thicknesses and numerical issues. When pockets are not fed or when there are no pockets, the minimum film thickness decreases almost linearly with the decrease of the rotor speed. It is obvious

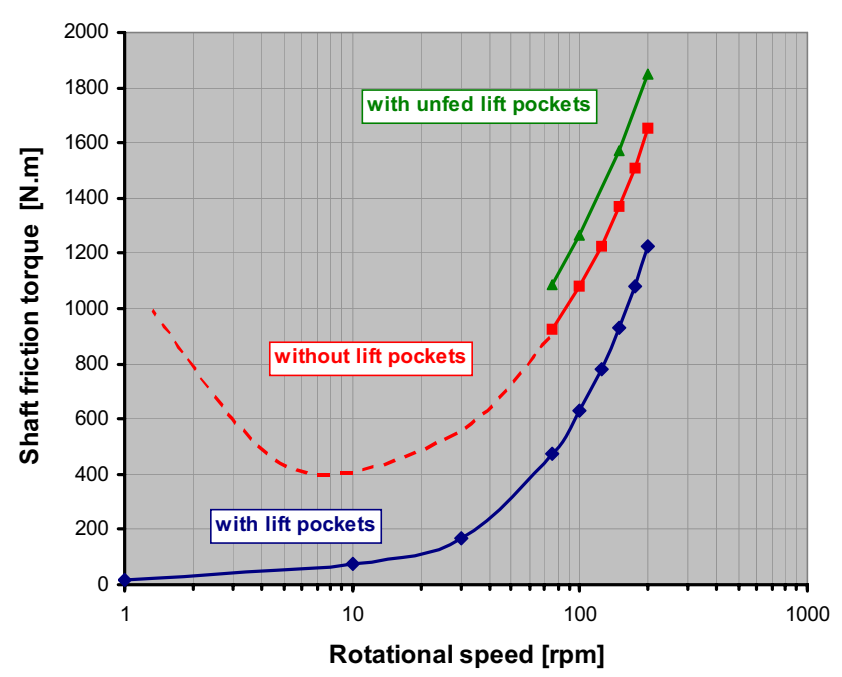

Fig. 7. Friction torque vs. rotor speed.

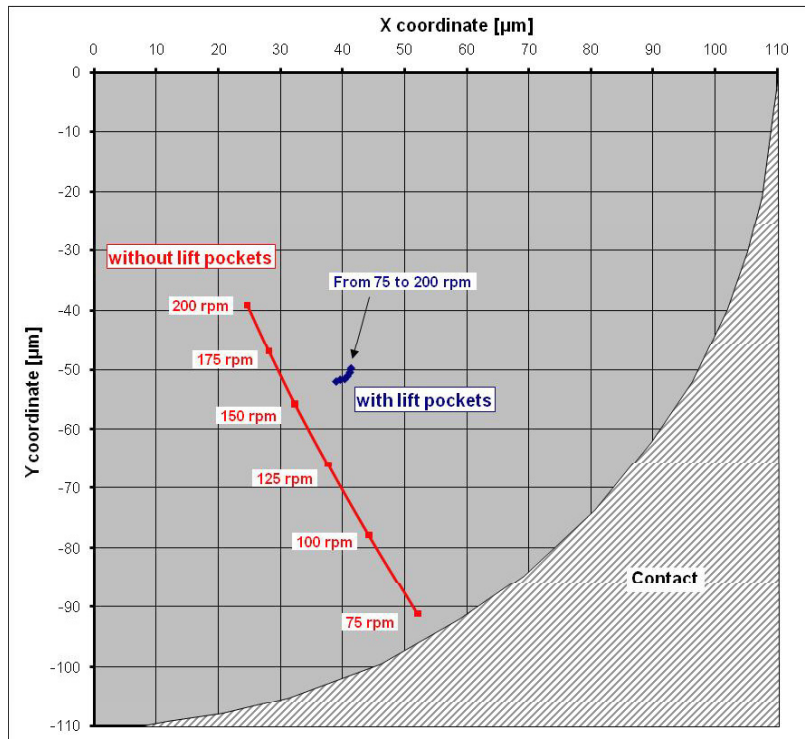

Fig. 8. Shaft center positions vs speed with and without lift pockets.

that a bearing with plain tilting pads does not work in safe operating conditions (i.e. film thickness under $40 \mu \mathrm{m}$ ) under $150 \mathrm{rpm}$. The conclusion is different for bearings with unfed pockets that lead to thinner film compared to the case with no pockets. If an extrapolation is made on the green curve (Fig. 6), safe operating conditions are reached only beyond about $400 \mathrm{rpm}$ for unfed pockets. The blue curves of Figure 6 deals with the bearing with correctly fed lift pockets: in this case, a minimum film thickness of about $75 \mu \mathrm{m}$ is ensured, even for very low rotational speeds.

Hydrostatic lift pockets have another interest in terms of friction torque: they dramatically reduce the initial effort requested for the turbo machinery start-up. Figure 7 illustrates, with the same colour code employed in Figure 6, the evolution of friction torque versus shaft 


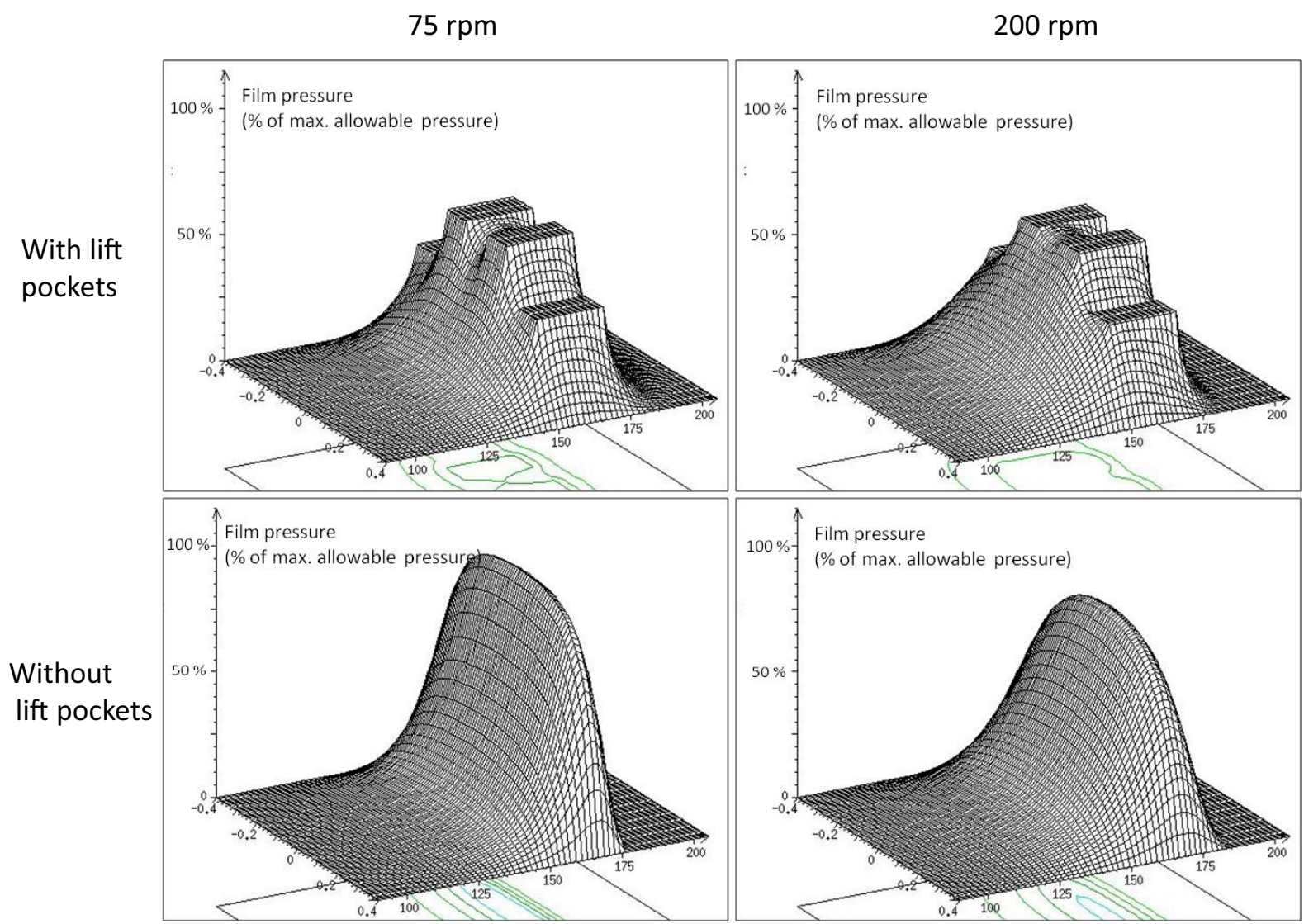

Fig. 9. Main pad pressure distribution, with and without lift pockets, for different rotor speeds.

rotational speed. The lifting effect, due to the presence of pockets, increases the film thickness and decreases consequently the shear stress in the film. Furthermore, this torque is quite negligible for extremely low speeds. Without pockets, friction torque is much higher and should even follow a "Stribeck style" curve if proper calculations under mixed lubrication regime could have been carried out. In this case, that would lead to an important increase of friction torque for extremely low speeds (dashed red curve of Fig. 7). The "pocket effect" can be also observed in Figure 8 where shaft center positions are plotted from $75 \mathrm{rpm}$ to $200 \mathrm{rpm}$ without lift pockets (red curve) and without pockets (blue curve). Without pockets, the eccentricity decreases with increase of rotor speed, going from quasi contact to "safer" positions while speed increases, whereas shaft trajectory is almost reduced to a single point in the case of a pocket equipped bearing.

\subsection{Pressure distribution}

Hydrostatic lift pockets, as seen in Section 4.1, have a huge impact on the global bearing performances. This can be explained by a large difference in the film pressure distribution through the bearing. The main pad pressure distribution is plotted in Figure 9, for two different bearings, with and without lift pockets, for two different shaft rotational speeds: $75 \mathrm{rpm}$ and $200 \mathrm{rpm}$. With lift pockets, pressure distribution and maximum pressure levels remain quite constant while speed increases. Without lift pockets, the pressure field is generated on a very narrow circumferential section, and thus leads to large maximum pressure levels that are required to insure the bearing load capacity. This is very noticeable in particular for low speeds. Thus, the benefit of lift pockets comes from the pressure field distribution that is better spread through a larger circumferential zone. This leads to lower maximum pressure, corresponding to safer working conditions. In conclusion, the hydrostatic pressure, produced by means of lift pockets, enables good rotor supporting characteristics without extreme hydrodynamic pressure levels that could lead to bearing damage.

\subsection{Effect on misalignment}

For hydrodynamic journal bearings, rotor misalignment breaks the pressure field symmetry and can lead, for bearings without lift pockets, to a tremendous increase of maximum film pressure and minimum film thickness diminution. On the other hand, for the same conditions of load and misalignment, a bearing with hydrostatic lift pockets can reduce this maximum film pressure to an acceptable level. For example, for the bearing described in Section 2, when submitted to a load of 200 tons, a rotational speed of $200 \mathrm{rpm}$ and a misalignment of $0.007^{\circ}$, the comparison between pockets and no pockets is displayed 

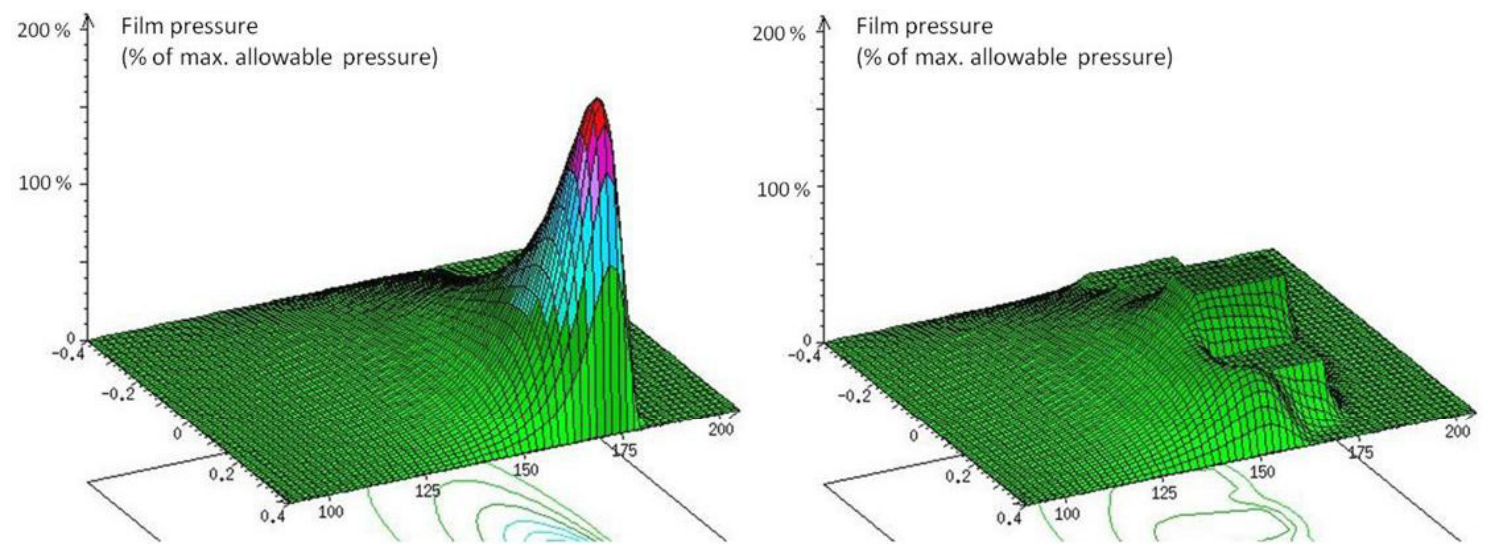

Fig. 10. Contribution of lift pocket on pressure field in presence of misaligned rotor.

Table 2. Effect of lift pockets with misalignment conditions.

\begin{tabular}{ccc}
\hline $\begin{array}{c}\text { Shaft misalignment }= \\
0.007^{\circ}\end{array}$ & $\begin{array}{c}\text { Without lift } \\
\text { pockets }\end{array}$ & $\begin{array}{c}\text { With lift } \\
\text { pockets }\end{array}$ \\
\hline Minimum film thickness & $10.3 \mu \mathrm{m}$ & $28.2 \mu \mathrm{m}$ \\
Maximum pressure (\% of & $210 \%$ & $74 \%$ \\
max. safe pressure) & & \\
Friction torque & 1660 N.m & 1280 N.m \\
\hline
\end{tabular}

in Table 2. The effect of lift pockets is an increase of $170 \%$ of minimum film thickness and a decrease of $65 \%$ of maximum pressure. In addition, the friction torque is reduced by about $23 \%$ with lift pockets.

The effect on maximum pressure is also displayed in Figure 10 where the pressure distribution on the main pad with a misaligned rotor is plotted. The presence of lift pockets tends to spread the pressure distribution in the circumferential direction, as seen in previous section, but also tends to balance the pressure field in the axial direction, leading to lower local maximum pressure levels.

\section{Perspective - bearing diagnosis}

Shaft misalignment in turbo generator sets can result of a poor tuning of the different turbo machinery bearing housings (altitude, rotation, etc.). The shaft flexion, due to its own weight can also lead to bearing misalignment if it is not properly evaluated. Furthermore, during nominal working conditions (1500 rpm), large shaft misalignment can cause unacceptable local film thickness and temperatures. Thus, the final effect is the Babbitt melting-up and the damage of the bearing leading to the turbo generator set stop and maintenance for up to several weeks. On one hand, this misalignment can be evaluated for low speed working conditions, for instance idle condition at $10 \mathrm{rpm}$, by means of the measured pressure in lift pockets (i.e. difference between pocket 2 and 3 of Fig. 4). On the other hand, several THD (ThermoHydroDynamic) calculations at high speed working conditions for different misalignment values could give the relation between misalignment and temperature and the acceptable limit of

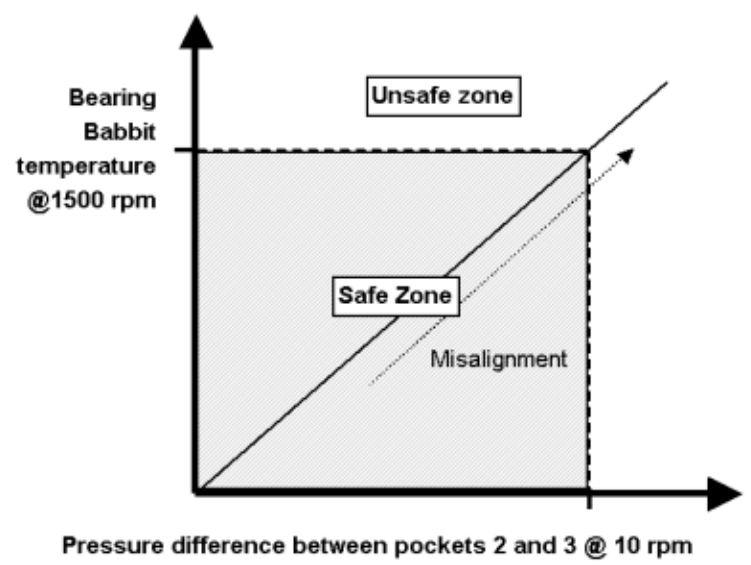

Fig. 11. Relation between pocket pressure and bearing temperature.

misalignment in order to insure safe working conditions. If the assumption of a same rotor flexion (shape) at low and high speeds is made, pressure difference in pockets at low speed can be correlated with temperature levels at high speed nominal working conditions. This principle is plotted in Figure 11. The main advantage of such an idea is the possibility of high speed temperature prediction with pressure measurements at low speeds. In conclusion, knowledge of pressure difference in 2 lift pockets during idle working conditions could help in decision of starting up the nominal high speed working conditions or improving bearings alignment and tuning before any damage has been occurred.

\section{Conclusion}

Hydrostatic lift pockets bring several advantages in heavy and complex rotor dynamic applications like turbo generator sets. Technical aspects of lift pockets have been presented for a concrete industrial application where hydrodynamic tilting pad bearings support very heavy rotors. The effect of lift pockets for such systems is 
safer operating conditions by means of film thickness increase and maximum pressure decrease for the very low rotational speeds. Thus, the risks of Babbitt damage or wear are reduced during start-up and shut-down working conditions. Lift pockets are also a good solution for reducing misalignment effects in tiling pad journal bearings. Finally, an opportunity for bearing diagnosis by pressure measurement in pockets has been proposed and has to be investigated.

\section{References}

[1] L. Dąbrowski, M. Wasilczuk, Influence of hydrostatic pump operation period on performance of a thrust bearing of a $125 \mathrm{MW}$ pump-turbine, 1st EDF \& LMS Poitiers Workshop, 2002
[2] M.M. Khonsari, E.R. Booser, Applied Tribology Bearing Design and Lubrication, John Wiley \& Sons, USA, 2001

[3] R.C. Elwell, Hydrostatic Lubrication, Handbook of lubrication, E.R. Booser, CRC, USA, 1984, Vol. II

[4] G.E. Totten, Handbook of Lubrication and Tribology: Application and Maintenance, 2nd edition, CRC Press, 2010, Vol. I

[5] M.J. Neale, Tribology Handbook, Newnes-Butterworths, 1975

[6] Progiciel EDYOS (Convention EDYOS CNRS No. L90119 du 4/02/1992)

[7] V.N. Constantinescu, Consideratii asupra lubrification tridmensionale in regim turbulent, Studii si Cereetari de Mecanica Applicata, t-4, No. 10, Acad. R.P.R (1959) $1093-112$ 